\title{
Memory for Grocery Prices in Younger and Older Adults: The Role of Schematic Support
}

\author{
Alan D. Castel \\ University of Toronto
}

\begin{abstract}
The present study examined how younger and older adults remember price information. Participants studied grocery items that were priced at market value or were well above or below market value. Although younger adults displayed better recall performance for unrealistic prices than older adults, there was no age difference for realistic prices, and both groups were equally accurate at remembering the general price range of the items. The results suggest that when older adults can rely on prior knowledge and schematic support, and tasks involve naturalistic materials, memory for associative information can be as good as that of younger adults.
\end{abstract}

Keywords: memory, aging, associative information, prices, expertise

The ability to remember numerical information such as phone numbers, addresses, personal identification numbers, and prices is essential given the varieties of numerical information that individuals must process every day. In most cases, it is important to link or associate numerical information with an appropriate context or item, such as recalling the prices of various items so that one can later make an informed purchase. Previous research has shown that older adults have impairments in a variety of tasks involving cued-recall and recognition tests of associative memory (Chalfonte \& Johnson, 1996; Kausler, 1994). Naveh-Benjamin (2000) suggested an associative deficit hypothesis to explain older adults' overall episodic memory impairments.

Although there is a great deal of research showing that older adults have difficulty remembering associative information involving verbal material, very little research has addressed age-related differences in the ability to remember numerical information that is linked to other items. Castel and Craik (2004) have shown that older adults have particular difficulty remembering specific arbitrary numeric information (such as the quantity information in the phrase "86 apples in the bowl"), but that expertise in a somewhat relevant domain such as accounting can reduce this age difference. Thus, older adults might show enhanced performance for numerical information that is consistent with already established forms of knowledge (see Mather \& Johnson, 2003), such as prices that reflect the market value of an item, relative to unrealistic prices.

Knowledge in a particular domain can facilitate memory for domain-relevant information (see Hambrick \& Engle, 2002, for a

This research was supported by the Natural Sciences and Engineering Research Council of Canada. Portions of this work were presented at the 10th Biennial Cognitive Aging Conference in Atlanta, GA. I thank Fergus Craik for his encouragement, guidance, and insight.

Alan D. Castel is now at the Department of Psychology, Washington University in St. Louis.

Correspondence concerning this article should be addressed to Alan D. Castel, Department of Psychology, Campus Box 1125, Washington University, One Brookings Drive, St. Louis, MO 63130-4899. E-mail: castel@wustl.edu review), but the investigation of how expertise and schema-based processing can reduce age-related differences has yielded mixed results. Hess and Slaughter (1990) found that older adults benefited from scene organization when trying to remember objects that varied in terms of the likelihood of occurrence in a particular scene. However, Morrow, Menard, Stine-Morrow, Teller, and Bryant (2001) found no evidence to suggest that aviation-related experience reduced the negative effect of age on memory for air-traffic control messages. Arbuckle, Cooney, Milne, and Melchior (1994) found that there was no reduction in age differences when prior knowledge could improve memory for prose passages or spatial layouts. However, one avenue that has yet to be thoroughly investigated is the degree to which task relevance in the everyday world (e.g., Neisser, 1978; see also Hess, 2005) influences how and when older adults rely on prior knowledge and remember numerical information. The use of numerical material (such as realistic and unrealistic prices) allows for a novel investigation of how arbitrary and more meaningful links between items can influence memory performance in younger and older adults.

The present investigation examined how younger and older adults remember grocery prices that are either consistent or inconsistent with an established form of knowledge or schema, such as prices that either reflect the market value of an item or are inconsistent with previous knowledge regarding this item. If older adults use prior knowledge of grocery prices to support episodic memory (a form of "schematic support," as described by Craik \& Bosman, 1992), then older adults might be able to better remember market value prices relative to prices that are inconsistent with prior knowledge.

\section{Experiment 1}

In Experiment 1, a paradigm was designed in which participants studied pictures of common grocery items paired with the item's price. In one condition, the prices were congruent with approximate market value of each grocery item (e.g., butter \$2.99); whereas in a second condition, the prices were all much higher than market value (e.g., soup \$14.39) and were randomly assigned 
to the items. It was expected that when the prices were congruent with approximate market value, participants could make use of these associations by relying on schematic support to help remember the prices, which might reduce age differences in the ability to remember the price-item pair. However, when the higher than market value prices were arbitrarily assigned to items, then younger adults would outperform older adults because there would be very little schematic support.

\section{Method}

Participants. Twenty-four undergraduate students from the University of Toronto ( 4 women and 20 men, mean age $=20.3$ years, mean number of years of education $=15.2$ ) volunteered to participate in exchange for course credit. Twenty-four older adults ( 17 women and 7 men, mean age $=$ 70.3 years, mean education $=15.4$ ) participated in the study and were paid $\$ 10$. The older adults in this and the following experiment were high functioning, in good health, lived in the community, and made their own way to the laboratory.

Materials and procedure. The stimuli were 40 pictures of common grocery items downloaded from a grocery shopping Web site on the Internet, and were selected such that they represented food items that were typically bought at grocery stores. The size of the pictures was kept relatively constant (approximately $5 \mathrm{~cm} \times 5 \mathrm{~cm}$ ), and they were presented in the center of the screen. Of these 40 pictures, 20 were randomly assigned to the market price condition, and the remaining 20 were assigned to the unusual price condition. Four different versions of the presentation list were created, such that items in the market price condition for 1 participant would appear in the overpriced condition for the next participant. In the market price condition, prices of each item were based on the actual market price of the item from the grocery shopping Web site, and these prices ranged from $\$ 1.19$ to $\$ 7.99$. In the overpriced condition, the market value price of each item was inflated by a random dollar value between 6 and 8 , so as to reduce predictability of the inflated price, and these prices ranged from $\$ 7.19$ to $\$ 15.99$. In both conditions, all prices ended in the digit 9 , and participants were made aware of this prior to the study session. The order of the conditions was counterbalanced such that participants began with either the market condition or the overpriced condition.

Participants were told that they would be studying grocery items and the prices of the items for a memory test later. In the market price condition, they were informed that the prices reflected the approximate market value of each item (i.e., a realistic price); in the overpriced condition, they were informed that the prices would be much higher than what they might expect to pay for the items. Participants were told that after studying 20 items, they would be given a memory test in which each item would be represented 1 at a time (in a random order), and they should try to recall the price of the item. In the test session, participants were told to provide an answer for each item, even if they could not remember the exact price of the item. During the study phase, each picture, the name of the item, and the corresponding price appeared on the center of the screen for $10 \mathrm{~s}$, with the name appearing above the picture in 44-point Times New Roman typeface. The next item appeared immediately afterward, and after the 20th item, an instruction screen appeared describing the memory test. Items were then presented without their price, and participants were instructed to recall the price of each item, and the experimenter recorded the response. At the end of the test session, participants were asked to rate on a 10-point scale how often they went grocery shopping.

\section{Results and Discussion}

The results are shown in Figure 1 in terms of the proportion of correctly recalled prices in each condition. Correctly recalled prices were defined as cases in which participants recalled the

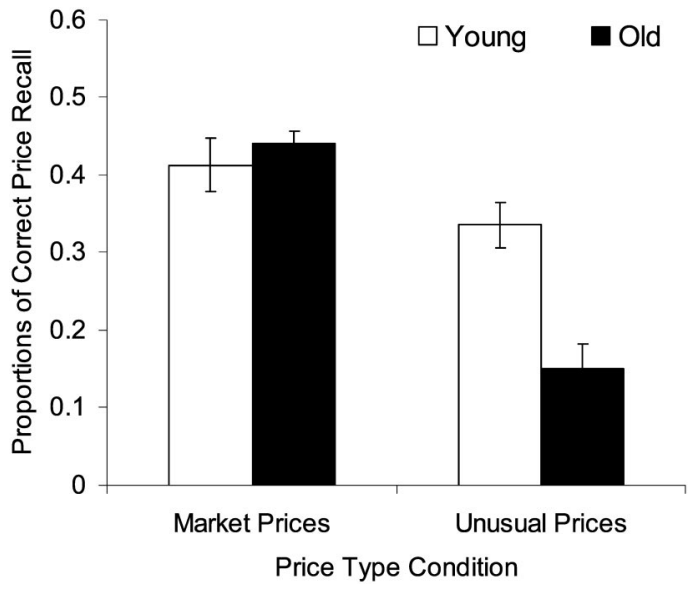

Figure 1. The proportions of correct price recall for the market value and unusual priced items by younger and older adults in Experiment 1. Error bars represent standard error of the mean.

exact price of the item. To determine if there was an effect of price type (market value or overpriced) on memory performance, and if this differed as a function of age group, a $2 \times 2$ repeated-measures analysis of variance (ANOVA) was conducted. There was a significant main effect of price type, $F(1,46)=92.87, M S E=3.51$, $p<.001$ (market prices were better recalled than over priced items), and age group, $F(1,46)=4.98, M S E=11.76, p<.05$ (young adults recalled more than older adults), as well as a significant interaction between age group and price type, $F(1$, 46) $=31.45, M S E=3.51, p<.01$. The interaction was driven by younger adults outperforming older adults in the overpriced condition, $t(46)=5.81, p<.0001$, but no age difference was present in the market price condition, $t(46)=-0.63, p=.53$.

One way to examine incorrect responses provided by participants is in terms of the deviation between the actual price and the response, resulting in an absolute deviation score reflecting how close the incorrect response was to the actual price. In the market value condition, the mean deviation for younger adults was $\$ 0.59$ $(S E M=0.05)$, while the mean deviation for older adults was $\$ 0.63$ $(S E M=0.07)$; these values were not significantly different, $t(46)=1.44, p=.87$. In the overpriced condition, the mean deviation for younger adults was $\$ 2.29(S E M=0.22)$, while the mean deviation for older adults was $\$ 2.98(S E M=0.36)$. Again, this difference was not significant, $t(46)=1.54, p=.21$. These results suggest that both groups provided an answer that was close to the actual value in the market value condition, perhaps by relying on prior knowledge of the prices in the absence of actually remembering the specific price. In the unusual price condition, the incorrect responses provided by both younger and older adults deviated by a larger amount than in the market value condition, but the observation that both groups were somewhat equivalent suggests that the older adults rarely provided a market value price for the unusually high priced items, and that both younger and older adults can remember the general nature of the price when retrieving price information.

One possible reason older adults performed well in the market value condition is that they have more grocery shopping experience relative to the younger university students. Older adults 
provided a higher rating $(M=8.1, S D=1.5)$ than younger adults $(M=5.1, S D=2.7)$, and this difference was significant, $t(46)=$ $4.74, p<.0001$. However, neither group showed significant correlations between rating and number of correct responses in either the market price condition or the overpriced condition (all $r \mathrm{~s}<$ $.24, p>.25$ ), suggesting that experience was not significantly related to performance, and that some general level of experience may provide sufficient beneficial effects of schematic support. To assess the degree to which knowledge about prices might influence performance in terms of correctly guessing a price, younger and older adults ( $n=6$ young and $n=6$ old) in a new group were presented with the grocery items without the prices and were asked to "guess" the market value price of each item. These participants, who did not participate in the original experiment, were told that they should guess the market price of each item (and that all prices ended in the digit 9) and were given several examples (e.g., a can of soup could be \$1.19). Using the prices from the present experiment as "correct" prices, out of the 20 items that were presented, younger adults correctly identified an average of 1.17 items, while older adults correctly identified an average of 0.67 items, which was a nonsignificant difference, $t(10)=1.10, p=.30$. The average deviation of the incorrect responses for younger adults was $\$ 0.93$, while the average deviation for older adults was $\$ 0.98$. Again, this difference was not significant, $t(10)=0.50, p=.63$. This control condition suggests that older adults do not have a differential advantage in terms of being able to correctly guess the actual market value prices.

The results show that when items are paired with market value prices, there are no age-related differences in later memory for the price information. However, when more arbitrary item-price pairings are studied, both groups show a reduction in performance, but younger adults outperform older adults. This may occur because younger adults can recall the precise numerical value of the overpriced items (an arbitrary association), whereas older adults may simply encode and retrieve the price information in a general manner, relying on gist information (e.g., Tun, Wingfield, Rosen, $\&$ Blanchard, 1998). Thus, a younger adult might recall that butter was exactly $\$ 17.89$, whereas an older adult simply recalls that the price was "well above market value" or "around 17 dollars." This issue is examined in Experiment 2.

\section{Experiment 2}

In Experiment 2, participants studied item-price pairs that were underpriced (e.g., \$0.39 for a jar of pickles), overpriced (\$17.89 for a jug of milk), or market value (\$1.89 for a head of broccoli). They were then given a cued-recall test for the prices as well as whether the items were overpriced, underpriced, or market value. It was hypothesized that older adults would be able to remember the specific prices of market value items as well as the younger adults, but that for both under- and overpriced items, younger adults would be more accurate at recalling the specific price. In terms of remembering the general category of the prices of each item, if older adults rely on an efficient form of gist-based memory, then these adults might be as good as younger adults at identifying underpriced, overpriced, and market value items.

\section{Method}

Participants. Twenty-four undergraduate students from the University of Toronto ( 20 women and 4 men, mean age $=18.5$ years, mean education $=13.3)$ volunteered to participate and received course credit for participation, and 24 older adults $(15$ women and 9 men, mean age $=69.9$ years, mean education $=15.8$ ) participated in the study and were paid $\$ 10$.

Materials and procedure. The materials were similar to those used in Experiment 1, with the addition of underpriced items. In total, 21 items were presented to participants ( 7 of each item type: market value, unrealistically high prices, and unrealistically low prices). Three versions of the presentation order and test order were used, and each consisted of different item-price pairing such that each item appeared equally often as an overpriced, underpriced, and market value pairing.

The procedure was identical to Experiment 1, except participants were told that they should try to remember both the price of each item and whether each item was overpriced, underpriced. or market value. Participants were also told that later they would have to recall both the price and the category of the price of each item.

\section{Results and Discussion}

The results for price recall of the three item types are shown in Figure 2A, and a repeated-measures ANOVA was conducted with age as the between-subjects variable. There was a main effect of price type, $F(2,92)=30.85, M S E=1.45, p<.0001$, with the prices of market value items being better recalled than over- and underpriced items. The effect of age approached significance, $F(1$, $46)=3.14, M S E=3.36, p=.08$, with younger adults recalling more prices than older adults. There was a significant interaction of age and price type, $F(2,92)=7.85, M S E=1.45, p<.01$. This interaction was driven by younger adults outperforming older adults for the under- and overpriced items $(p<.01)$, but no age-related difference was present for the market value items ( $p=$ .25), replicating the main findings from Experiment 1.

Participants were also asked to recall the general category of the price of each item, and the results are shown in Figure 2B. A repeated-measures ANOVA was carried out with age as the between-subjects variable. There was a main effect of price type, $F(2,92)=7.23, M S E=1.07, p<.01$, with market and overpriced items being better recalled in terms of price range than underpriced items. However, there was no significant main effect of age, $F(1$, 46) $=0.48, M S E=3.74, p=.49$, showing that both groups were equally good at remembering the price range of the items (although note both groups performed well and were near maximal performance). Finally, there was a significant interaction of age and price type, $F(2,92)=3.55, M S E=1.07, p<.05$, with older adults outperforming younger adults for the market value items $(p<.05)$. There were no age-related differences for the underpriced $(p=.55)$ or overpriced $(p=.62)$ items.

In terms of remembering the general category of the prices of each item, older adults were just as good as younger adults at identifying underpriced, overpriced, and market value items, suggesting that at this level of analysis there are negligible age-related differences in terms of memory for associative information. This finding implies that gist-based representations are well maintained by older adults, but it is also possible that older adults used a form of reasoning when recalling the price category (e.g., recalling the price and then reasoning the value category) or were more inclined to utilize gist-based encoding or retrieval given the nature and instructions of the task. 
A

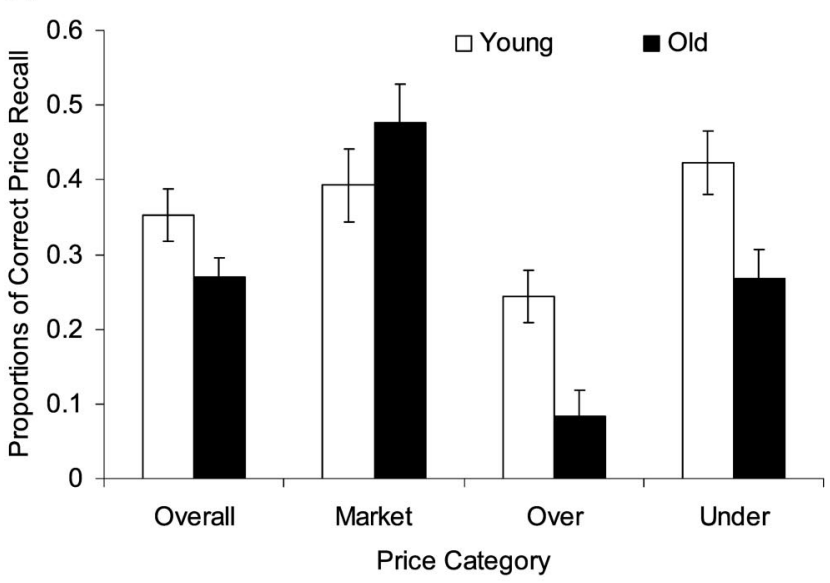

B

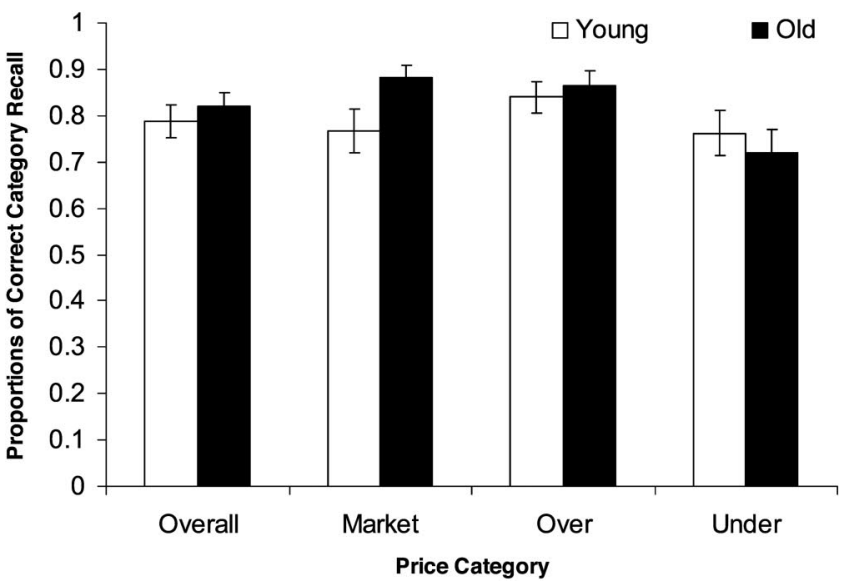

Figure 2. The results from Experiment 2, in terms of the proportions of correct price recall for the underpriced, overpriced, and market value items by younger and older adults (Figure 2A) and the proportions of correct recall of the general price category for underpriced, overpriced, and market value items by younger and older adults (Figure 2B). Error bars represent standard error of the mean.

\section{General Discussion}

The striking finding from the present study is that although age differences were apparent for arbitrarily overpriced and underpriced items, age differences were not present for realistic market value prices. The present results fit with other work that shows that age differences are reduced as a function of materials and task goals. For example, Fung and Carstensen (2003) found that older adults had better memory for advertisements that promised to help realize emotionally meaningful goals relative to other types of advertisements. Rahhal, May, and Hasher (2002) found that although older adults had difficulty remembering the voice that spoke a statement of information, when older adults were told that the speaker's voice indicated whether the statement was true or false, they displayed exceptional memory for the truthfulness of these statements. These findings suggest that when memory tasks involve meaningful and naturalistic information, age-related differences can be reduced or eliminated.
Although several studies have found that age differences are not reduced when one can rely on prior knowledge and schematic support, this may be because the process of integrating new information with the schema itself requires resources that are reduced in older adults (Arbuckle et al., 1994). In the present context, this integration process might be facilitated for older adults because of the nature of the task and because naturalistic materials induce evaluative processing about the price of items. The present study does not provide a precise explanation for how older adults remember general and specific associations between items and various prices, but the findings suggest that schematic support and prior knowledge by younger and older adults are important factors that influence memory performance across the life span.

\section{References}

Arbuckle, T. Y., Cooney, R., Milne, J., \& Melchior, A. (1994). Memory for spatial layouts in relation to age and schema typicality. Psychology and Aging, 9, 467-480.

Castel, A. D., \& Craik, F. I. M. (2004, April). Memory for numerical information in younger and older adults: The role of schematic support. Poster presented at the 10th Biennial Cognitive Aging Conference, Atlanta, GA.

Chalfonte, B. L., \& Johnson, M. K. (1996). Feature memory and binding in young and older adults. Memory \& Cognition, 24, 403-416.

Craik, F. I. M., \& Bosman, B. A. (1992). Age-related changes in memory and learning. In H. Bouma \& J. A. M. Graafmans (Eds.), Gerontechnology (pp. 79-92). Amsterdam: IOS Press.

Fung, H. H., \& Carstensen, L. L. (2003). Sending memorable messages to the old: Age differences in preferences and memory for advertisements. Journal of Personality and Social Psychology, 85, 163-178.

Hambrick, D. Z., \& Engle, R. W. (2002). Effects of domain knowledge, working memory capacity, and age on cognitive performance: An investigation of the knowledge-is-power hypothesis. Cognitive Psychology, 44, 339-387.

Hess, T. M. (2005). Memory and aging in context. Psychological Bulletin, 131, 383-406.

Hess, T. M., \& Slaughter, S. J. (1990). Schematic knowledge influences on memory scene information in young and older adults. Developmental Psychology, 26, 855-865.

Kausler, D. H. (1994). Learning and memory in normal aging. New York: Academic Press.

Mather, M., \& Johnson, M. K. (2003). Affective review and schema reliance in memory in older and younger adults. American Journal of Psychology, 116, 169-189.

Morrow, D. G., Menard, W. E., Stine-Morrow, E. A. L., Teller, T., \& Bryant, D. (2001). The influence of expertise and task factors on age differences in pilot communication. Psychology and Aging, 16, 31-46.

Naveh-Benjamin, M. (2000). Adult age differences in memory performance: Tests of an associative deficit hypothesis. Journal of Experimental Psychology: Learning, Memory, and Cognition, 26, 1170-1187.

Neisser, U. (1978). Memory: What are the important questions? In M. M. Gruneberg, P. Morris, \& R. N. Sykes (Eds.), Practical aspects of memory (pp. 3-24). London: Academic Press.

Rahhal, T. A., May, C. P., \& Hasher, L. (2002). Truth and character: Sources that older adults can remember. Psychological Science, 13, 101-105.

Tun, P. A., Wingfield, A., Rosen, M. J., \& Blanchard, L. (1998). Response latencies for false memories: Gist-based processes in normal aging. Psychology and Aging, 13, 230-241.

Received November 1, 2004

Revision received June 9, 2005

Accepted June 28, 2005 